\title{
Produção técnico-científica dos bibliotecários do Instituto Federal de São Paulo: Um estudo neobibliométrico
}

\author{
Technical-scientific production of the librarians of SãoPaulo's Federal Institute: \\ A Neo-Bibliometric Study
}

Cintia Almeida da Silva Santos ${ }^{1}$, Fernanda Rodrigues Pontes ${ }^{2}$

${ }^{1}$ Universidade Federal de São Carlos

2Instituto Federal de Educação, Ciência e Tecnologia de São Paulo

RESUMO: As bibliotecas e os bibliotecáriosdocumentalistas do Instituto Federal de Educação, Ciência e Tecnologia de São Paulo (IFSP) têm sido objeto de estudo de pesquisas científicas, porém, ainda não foi identificada nenhuma investigação que levantasse e mapeasse a produção científica desses profissionais. Este estudo objetivou mapear e analisar a produção técnico-científica dos bibliotecáriosdocumentalistas da referida instituição. O percurso metodológico compreendeu a realização de pesquisa teórico-empírica, na qual foi priorizada a abordagem neobibliométrica; nesse sentido, o ferramental da bibliotemetria foi associado à aplicação de questionário aos profissionais da instituição. Os resultados apontaram que a maioria dos profissionais do IFSP: é do gênero feminino; possui qualificação superior à exigida para o desempenho de suas funções; possui alguma publicação técnico-científica; considera importante a elaboração de publicações técnico-científicas, assim como a criação de veículos de comunicação e eventos. Todavia, as autoras sugerem alguns caminhos para o fortalecimento da visibilidade da categoria: incentivo ao aumento das publicações técnico-científicas; incentivo à criação e atualização do currículo lattes; incentivo à realização de publicações em parcerias, visto que alguns profissionais pesquisam temáticas similares; estímulo à participação em eventos e publicações técnicocientíficas. As considerações apontam que os bibliotecários-documentalistas do IFSP produzem publicações técnico-científicas, mas poderão produzir mais, visto que tal feito contribui para o desenvolvimento e aperfeiçoamento da categoria, aproxima relações institucionais entre os câmpus, favorece a busca de soluções para os problemas enfrentados pelos profissionais, além de evidenciar seus câmpus e suas bibliotecas no cenário técnicocientífico nacional e internacional.

PALAVRAS-ChAVE: Produção Científica. Bibliotecários. Instituto Federal de São Paulo. Bibliometria.

\section{Correspondência}

${ }^{1}$ Cintia Almeida da Silva Santos Universidade Federal de São Carlos.

São Carlos, SP.

Email: cintiaassantos@gmail.com

ORCID: http://orcid.org/0000-0002-1832-3751
ABSTRACT: Libraries and librarians-documentalists of São Paulo Federal Institute of Education, Science and Technology (IFSP) have been studied in scientific researches, but no identified that would raise and map scientific production of such professionals has been conducted yet. The present study aimed to map and analyze the technical-scientific production of librarians-documentalists of the referred institution. The methodological course consisted of conducting theoretical and empirical research, in which the neobibliometric approach was prioritized. Then, the tools of Bibliometrics were associated with the application of questionnaire to the professionals of the institution. The results pointed out that most of IFSP professionals: are female; have higher qualification to the one required for the performance of their duties; have some technical-scientific publications; consider important the development of technical-scientific publications, as well as the creation of media and events. However, the authors suggest some ways to strengthen the visibility of the professional area: incentive to increase technical-scientific publications; incentive to the creation and updating of the curriculum lattes; incentive to publications in tandem, since some professionals research similar themes; stimulus to the participation in events and technicalscientific publications. The conclusion of this paper points out that IFSP librarians-documentalists produce technical-scientific publications, but they may produce them more as it contributes to the development and improvement of their professional area. It also draws closer institutional relations among campuses, favors the search for solutions to the problems faced by professionals, as well as highlights their campuses and libraries in national and international technical-scientific scenario.

KEYWORDS: Scientific Publications. Librarians. São Paulo Federal Institute. Bibliometrics. 


\section{INTRODUÇÃO}

É possível perceber o aumento nas produções científicas direcionadas a contribuir para o desenvolvimento laboral de diversas áreas nas instituições de ensino. Essa iniciativa se dá pela valorização desse tipo de participação e pelo interesse de profissionais de alcançar a ciência no sentido de aprimorar o seu próprio campo de trabalho, atingindo beneficamente o público que atende. Ficar de braços cruzados esperando que alguém desenvolva pesquisas para seu benefício profissional e social não é o perfil da atual sociedade do conhecimento. Esta já havia sido defendida por Bell (1978) - embora o autor não tenha usado essa nomenclatura - através de discussões sobre uma sociedade baseada nas tecnologias e no conhecimento sustentável.

Segundo Nehmy e Paim (2002), Bell desenvolveu um pensamento para essa nova sociedade, para Dziekaniak e Rover (2011), Bell baseava a sociedade do conhecimento em critérios como a alteração no setor de serviços. Uma vez que cresceriam os cargos vinculados ao conhecimento, o conhecimento iria servir como mola propulsora de concorrência entre empresas, de forma que pesquisa, desenvolvimento e inovações tecnológicas passariam a ser o centro da atenção dos países que buscam o desenvolvimento. Haveria a criação de uma "elite do conhecimento", que seria a classe dominante nessa sociedade, ou seja, quem detivesse conhecimento deteria o poder.

Foucault corrobora com a afirmativa quando disserta que "o exercício do poder cria perpetuamente conhecimento, e ao contrário, o conhecimento constantemente gera efeitos de poder" (FOUCAULT, 1988).

Isto posto, Davenport e Prusak na década de noventa já discorriam em conferências e artigos, o interesse da sociedade pelo conhecimento, pois este é fundamental para o sucesso das organizações, ou melhor para a sobrevivência humana (DAVENPORT; PRUSAK, 1999).

Em decorrência da necessidade, por parte de profissionais de diversas áreas, de se adaptarem às novas exigências do mercado diante da busca pela inovação e sua aplicação no ambiente de trabalho, muitos mergulham no mundo da ciência e do conhecimento. Nessa realidade, alguns indicadores têm sido compostos para avaliar o nível de produção científica e a capacidade desses novos profissionais de participar dessa nova era designada Sociedade do Conhecimento.

Em meio a essa sociedade que contemporaneamente evidencia a importância da informação e do conhecimento estão inseridos os Institutos Federais de Educação, Ciência e Tecnologia, ou Institutos Federais, como popularmente conhecidos, os quais fazem parte da Rede Federal de Educação Profissional, Científica e Tecnológica. Cada estado brasileiro possui ao menos um Instituto Federal, estes buscam oferecer qualificação educacional, técnica, científica e profissional na territorialidade em que estão inseridos (INSTITUTO FEDERAL DE SÃO PAULO, 2015). 
As bibliotecas e os bibliotecários-documentalistas dos Institutos Federais de Educação, Ciência e Tecnologia de São Paulo (IFSP) têm sido objeto de estudo de algumas pesquisas técnico-científicas, porém, ainda não foi identificada nenhuma investigação que levantasse e mapeasse a produção científica dos referidos profissionais do IFSP.

Nesse sentido, o presente estudo se apresenta com o objetivo de iniciar o preenchimento desta lacuna, de forma a suscitar discussões para futuras investigações mais aprofundadas.

A problemática que circundou a pesquisa se instala no interesse das autoras, especificamente com relação ao mapeamento e análise da produção técnico-científica dos bibliotecários-documentalistas do IFSP. Também há o interesse conjunto de identificar se a prática das produções técnico-cientificas por esses profissionais contribui para 0 desenvolvimento profissional e científico e para a solução de problemas com vistas ao aprimoramento de suas práticas laborais.

O percurso metodológico compreendeu a realização de pesquisa teórico-empírica, na qual foi priorizada a abordagem neobibliométrica aliada a aplicação de questionário aos bibliotecários do IFSP. A coleta de dados foi feita em duas frentes: primeiro foi aplicado um questionário aos profissionais, e posteriormente foram verificadas informações referentes às produções bibliográficas no currículo lattes desses profissionais.

Os resultados apontaram que os bibliotecários-documentalistas produzem materiais técnico-científicos, e que à partir do estudo foi possível traçar um perfil sumário desses profissionais, informações estas apresentadas na quarta seção do artigo.

As considerações apontam que os bibliotecários-documentalistas do IFSP produzem publicações técnico-científicas, mas poderão produzir uma quantidade ainda maior; poderão também realizar parcerias institucionais entre os profissionais dos diferentes câmpus do IFSP, com vistas a melhorias em suas rotinas de trabalho, assim como aumentar as publicações técnico-cientificas, gerando visibilidade para suas instituições e trabalhos colaborativos.

O estudo está distribuído como segue: a primeira e referida seção apresenta a Introdução da Pesquisa; a segunda seção remete ao Referencial Teórico que foi utilizado acerca das temáticas de produção científica e atuação profissional do bibliotecário. $\mathrm{Na}$ terceira seção, é apresentado o Percurso Metodológico, compreendido pelas subseções: Campo de Análise, Instrumento de Coleta e Análise de Dados, e as teorias que circundam a neobibliometria. Os Resultados e Análise dos Dados são tratados na quarta seção; na quinta seção, são feitas as Considerações Finais e, em seguida, apresentam-se as Referências utilizadas na elaboração da pesquisa. 


\section{REFERENCIAL TEÓRICO}

\subsection{Produção Científica}

Nas últimas décadas, a produção científica passou a ser um indicador importante de desenvolvimento de uma nação, tanto que as universidades brasileiras, polos do desenvolvimento científico nacional, passaram a estimular os pesquisadores a produzir e publicar em periódicos internacionais como forma de tornar suas pesquisas internacionalmente reconhecidas e, assim, valorizar tanto a instituição na qual o pesquisador está inserido como seu país (SILVA, 2013).

Ferreira (2011) defende que o propósito primordial das universidades e dos institutos de pesquisa é produzir conhecimento, uma vez que a qualidade do ensino e o reconhecimento da universidade estão relacionados à quantidade de pesquisas desenvolvidas e direcionados aos problemas da sociedade onde está inserida, isso tudo a partir de uma produção científica que responda às necessidades dessa sociedade.

Como instituição geradora de conhecimento, as universidades, assim como os Institutos Federais também vêm se mostrando colaboradores das atividades de pesquisa desenvolvidas pelos profissionais que atuam nos diversos setores. Essa colaboração se dá para além do interesse de se autopromover no meio científico, e sim como forma de difundir o conhecimento na sociedade. Nesse sentido, Schwartzman e Castro (1986) consideram a produção científica algo tangível, que pode ser avaliado e contado; caso contrário, perde-se o sentido da atividade científica cujos desenvolvimentos e resultados não são descritos e comunicados.

Isto posto, são necessárias técnicas e ferramentas que possibilitem a verificação da procedência e da credibilidade da produção científica e é neste contexto que a bibliometria está inserida, pois consiste na utilização de técnicas matemáticas e estatísticas para realizar a medição de índices da produção e da disseminação da produção científica, fazendo uso de métodos quantitativos para possibilitar avaliações objetivas, destacam os autores Guedes; Borschiver (2005) e Vanz; Stumpf (2010).

Vê-se que o avanço da produção científica se expande para um avanço da sociedade. Assim, é cabível destacar os autores Bordons e Zulueta-Garcia (1999), que fundamentam, em algumas premissas, que o número de publicações de um grupo de pesquisa pode representar um indicador de sua produtividade.

Os autores valorizam o contexto da pesquisa, desde que ela não seja apenas um montante de informação e sim um conjunto de saberes produzidos, pois dessa forma se socializa conhecimento e as descobertas relevantes para a história e o avanço da sociedade.

Schwartzman e Castro (1986) alertam que, ao levantar as publicações de uma área de 
conhecimento específica, pode-se medir sua produção científica em um período anterior. Isso fundamenta as decisões de buscar pontos de relevância entre uma pesquisa e outra, avaliar o grau científico das publicações e verificar se tudo está associado. Assim, deve haver uma triagem prévia, em termos de nível de qualidade, do material tratado. Nesse caso, porém, a bibliometria fracassaria se tivesse que criar seus próprios critérios externos de avaliação. $\mathrm{O}$ que se faz, portanto, é julgar os critérios de qualidade dos periódicos.

A produção científica vem se intensificando nos aspectos quali-quantitativos desde a segunda metade do século XX. Isso se deu, segundo Souza e Oliveira (2007), pelo aumento exponencial de produção e consumo de informação, que caracterizou o conhecido "boom bibliográfico", ou "explosão bibliográfica".

Ainda, Souza e Oliveira (2007), pode-se dizer que o fenômeno informacional passou a ser tema de discussões em várias áreas do conhecimento, principalmente naquelas diretamente ligadas à produção e comunicação, como a Biblioteconomia e a Ciência da Informação.

Nesse sentido, o profissional bibliotecário acaba por adquirir familiaridade com o universo investigativo, pois a essência de sua atuação está envolta no aprender, ou seja, no ato de investigar, buscar conhecimento (CBO, [s.d.]).

\subsection{Atuação Profissional do Bibliotecário: A Importância da Prática da Pesquisa Técnico- Científica}

Na contemporaneidade, o profissional bibliotecário precisa ser criativo, reflexivo e ponderado. Há a necessidade premente de aprender a aprender, como apontam as autoras Silva, Silva e Santos-Rocha (2013, p. 104).

Araújo afirma que aprender a aprender se torna possível somente por meio da pesquisa científica, que deve ser compreendida como um princípio pedagógico capaz de proporcionar ação e reflexão dos envolvidos perante os conhecimentos adquiridos (ARAUJO, 1996).

No cenário nacional, a profissão de bibliotecário, regulamentada pela Lei nº 4.084 de 30 de junho de 1962, privativa aos Bacharéis em Biblioteconomia, conforme Ferreira e Veiga (2013), ainda se destaca como uma profissão com predominância do gênero feminino, pois aproximadamente $80 \%$ dos cargos de bibliotecários nas instituições são ocupados por mulheres.

Conforme o Artigo $6^{\circ}$ da referida Lei, são atribuições dos Bacharéis em Biblioteconomia a organização, direção e execução dos serviços técnicos de repartições públicas federais, estaduais, municipais e autárquicas e empresas particulares concernentes às matérias e atividades seguintes: 
1. O ensino de Biblioteconomia;

2. A fiscalização de estabelecimentos de ensino de Biblioteconomia reconhecidos, equiparados ou em via de equiparação;

3. Administração e direção de bibliotecas;

4. A organização e direção dos serviços de documentação;

5. A execução dos serviços de classificação e catalogação de manuscritos e de livros raros e preciosos, de mapotecas, de publicações oficiais e seriadas, de bibliografia e referência (BRASIL, 1962).

A Classificação Brasileira de Ocupações (CBO) descreve as atividades sumárias do profissional da informação, como se apresenta:

Disponibilizam informação em qualquer suporte; gerenciam unidades como bibliotecas, centros de documentação, centros de informação e correlatos, além de redes e sistemas de informação; tratam tecnicamente e desenvolvem recursos informacionais; disseminam informação com o objetivo de facilitar o acesso e geração do conhecimento; desenvolvem estudos e pesquisas; realizam difusão cultural; desenvolvem ações educativas; podem prestar serviços de assessoria e consultoria (CBO, [s.d.]).

Tais atividades perpassam desde a gestão e a organização de ambientes que lidam com informação, nos mais variados suportes, até a realização de estudos e pesquisas, Rezende (2002) discorre que os profissionais da informação podem atuar como agentes criativos, intérpretes, intermediários e como gestores do conhecimento, pois podem utilizar a informação na solução de problemas ou como insumo gerador de ideias que poderão fundamentar novas tecnologias e conceitos.

Demo (1998) dialoga que a educação e a pesquisa devem caminhar juntas e em conformidade. Desse modo, a prática da pesquisa científica, assim como a técnica, são relevantes aos bibliotecários, na medida em que podem gerar novas informações, solucionar problemas, fortalecer os processos laborais e ainda contribuir para o avanço da área de conhecimento por intermédio das pesquisas técnicas e científicas.

Nas rotinas diárias, particularmente em bibliotecas, as atividades dos bibliotecários estão envoltas em pesquisas e localização de informações, tanto para o desempenho de suas atribuições quanto para dirimir as dúvidas e problemas informacionais dos usuários. Nesse sentido, publicar os resultados e as inquietudes de suas rotinas é tão importante quanto pesquisar, pois isso registra e possibilita formas de compartilhar experiências vividas, inquietudes, avanços e inovações que podem ser utilizadas e adaptadas em diferentes realidades.

O profissional bibliotecário que emergir das pesquisas científicas será antes de tudo um bibliotecário pesquisador, que se traduzirá em um profissional com diferentes facetas, dotado de proficiência e criatividade para propor e solucionar problemas, além de contribuir para os avanços da Biblioteconomia e Ciência da Informação, como destacam Silva, Silva e 
Santos-Rocha (2013).

No contexto do IFSP as atribuições inerentes ao cargo de bibliotecário-documentalista também perpassam questões relacionadas a realização de estudos e pesquisas, visto que o referido profissional deve se manter em constante atualização para desenvolver as bibliotecas nas quais atual, auxiliar na preservação da memória institucional, assim como atender as necessidades informacionais de sua comunidade (BRASIL. DIÁRIO OFICIAL DA UNIÃO, 2015).

Especificamente com relação ao desenvolvimento de estudos e pesquisas, seguem as descrições típicas do cargo:

Desenvolver estudos e pesquisas: coletar informações para memória institucional; elaborar dossiês de informações, pesquisas temáticas, levantamento bibliográfico e trabalhos técnico-científicos; acessar bases de dados e outras fontes em meios eletrônicos; realizar estudos cientométricos, bibliométricos e infométricos; analisar, coletar dados estatísticos; desenvolver critérios de controle de qualidade e conteúdo de fontes de informação; analisar fluxos de informações comunidade (BRASIL. DIÁRIO OFICIAL DA UNIÃO, 2015).

Assim, verifica-se que ser um profissional, sobretudo pesquisador, também compete aos profissionais bibliotecários-documentalistas do IFSP.

\section{PERCURSO METOdOLÓGICO}

O percurso metodológico compreendeu a realização de pesquisa teórico-empírica, na qual foi priorizada a abordagem neobibliométrica. Nesse sentido, o conceito e o ferramental da bibliometria foram associados à aplicação de questionário sociocultural.

Salienta-se que nesse contexto está imbuída a pesquisa bibliográfica, necessária em toda e qualquer investigação, pois fornece subsídios teóricos que sustentam o estudo. Assim, foram feitos levantamentos em livros e periódicos (RAMPAZZO, 2005, p. 53).

A pesquisa teórico-empírica proporcionou maior familiaridade com o problema de pesquisa (GIL, 2008), que consistiu em identificar se os bibliotecários do IFSP produzem e publicam pesquisas técnicas e científicas e se essas produções contribuem para o desenvolvimento profissional e para a solução de problemas com vistas ao aprimoramento de suas práticas laborais.

O estudo compreendeu o levantamento bibliográfico e a utilização dos instrumentos de coleta e análise dos dados, configurando uma análise neobibliométrica, ou seja, houve a possibilidade do levantamento de indicadores da produção bibliográfica aliada à aplicação de questionários aos profissionais.

De acordo com Smit, Dias e Souza (2002, p.4), a produção bibliográfica é "um dos produtos mais visíveis da pós-graduação", pois, através dela, pode-se levantar indicadores 
quantitativos dessas produções e é neste cenário que está inserida a bibliometria.

Assim, ratifica-se a importância das produções bibliográficas na vida científica de todo pesquisador. Partindo do pressuposto de que o bibliotecário pode atuar também como um pesquisador, é significativo mapear e analisar suas produções bibliográficas.

\subsection{Campo de Análise}

O campo de análise da pesquisa compreende os bibliotecários-documentalistas do IFSP. A instituição é uma autarquia federal de ensino, fundado em 1909 originalmente como Escola de Aprendizes e Artífices, que atualmente se traduz em uma instituição reconhecida pela sociedade paulista por sua excelência no ensino público gratuito de qualidade (INSTITUTO FEDERAL DE SÃO PAULO, 2015).

Durante sua trajetória, passou por diversas mudanças, e recebeu os nomes de Escola Técnica Federal de São Paulo e Centro Federal de Educação Tecnológica de São Paulo. Com a transformação em Instituto, em dezembro de 2008, passou a ter relevância de universidade, destacando-se pela autonomia (INSTITUTO FEDERAL DE SÃO PAULO, 2015).

Com a mudança, o Instituto Federal de São Paulo passou a destinar 50\% das vagas para os cursos técnicos e, no mínimo, 20\% das vagas para os cursos de licenciatura, sobretudo nas áreas de Ciências e da Matemática. Complementarmente, continuará oferecendo cursos de formação inicial e continuada, tecnologias, engenharias e pósgraduação (INSTITUTO FEDERAL DE SÃO PAULO, 2015).

Além dos cursos presenciais, o IFSP oferece os cursos Técnicos em Administração e em Informática para Internet e, a partir de 2012, o superior de Formação de Professores na modalidade de Ensino a Distância (INSTITUTO FEDERAL DE SÃO PAULO, 2015).

O IFSP é organizado em estrutura multicâmpus e possui aproximadamente 24 mil alunos matriculados nos 31 câmpus e mais 4 mil alunos nos 19 polos de educação a distância distribuídos pelo estado de São Paulo (INSTITUTO FEDERAL DE SÃO PAULO, 2015). A Figura 1 apresenta as localidades de cada câmpus: 


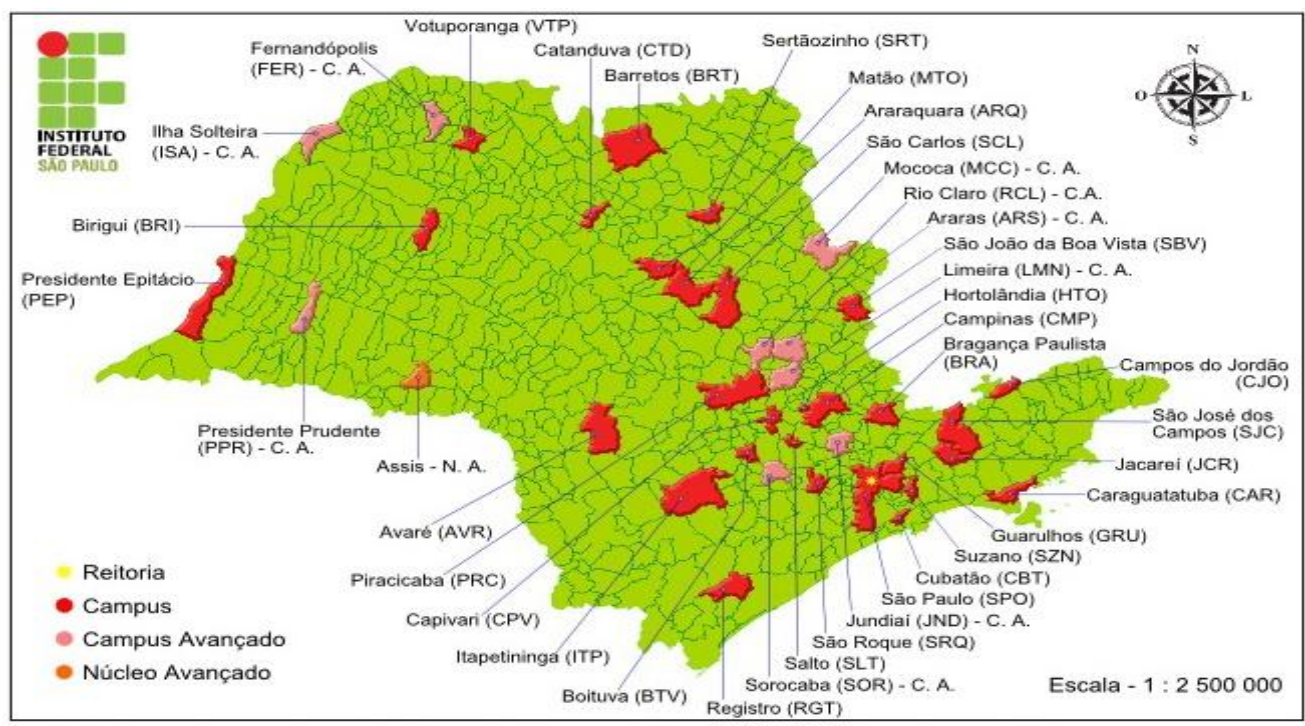

Figura 1. Instituto Federal de Educação, Ciência e Tecnologia de São Paulo, mapa dos câmpus 2016. Fonte: SIMEC (2016).

A contextualização do IFSP se fez necessária para destacar a função multitopologia que circunda suas bibliotecas. Alguns estudos versam sobre a temática das bibliotecas do IFSP, que ainda não possui um conceito cunhado.

A identidade das bibliotecas dos Institutos Federais de maneira geral está sendo construída, pois congrega diferentes perfis de usuários e, por consequência, diferentes necessidades em um mesmo ambiente. Dessa forma, é válido investigar o perfil dos profissionais que atuam nesses ambientes, assim como o perfil dos usuários que utilizam estas bibliotecas.

Santos definiu as bibliotecas do IFSP como sistemas informativos que devem prestar assessoria tanto aos processos de ensino-aprendizagem quanto aos processos científicos e extensionistas de seus respectivos câmpus, de maneira que possam satisfazer às necessidades informacionais de seus usuários (SANTOS, 2012, p. 80).

No IFSP, cada câmpus conta ao menos com dois bibliotecários-documentalistas. Conforme contato telefônico com a Gerência de Administração de Pessoal (GAP), o quadro de bibliotecários-documentalistas em março de 2016 era de 59 profissionais.

\subsection{Instrumentos de Coleta e Análise de Dados}

A coleta de dados foi feita em duas frentes. Primeiro, foi aplicado um questionário e, posteriormente, foram verificadas informações referentes às produções bibliográficas no currículo lattes dos profissionais. 
A identificação dos profissionais foi feita de acordo com as informações disponíveis nos sites oficiais de cada câmpus. Tal identificação serviu para o direcionamento das pesquisas na Plataforma Lattes.

Com relação à utilização do questionário, o mesmo foi composto por 17 questões semiestruturadas, sendo 14 de múltipla escolha e 3 dissertativas. O questionário foi enviado ao grupo de profissionais em 24 de fevereiro de 2016 através de e-mail institucional. Foi utilizada a ferramenta Google Forms para elaboração compartilhada do instrumento. A fonte de pesquisa utilizada para consulta das produções técnico-científicas e posteriores análises bibliométricas foi a Plataforma Lattes.

As respostas puderam ser enviadas até 31 de março de 2016. Para analisar o corpus investigativo da pesquisa, optou-se pela análise neobibliométrica, em que foram aliados os indicadores oriundos tanto da aplicação do questionário quanto do mapeamento feito no campo Produção Bibliográfica do currículo lattes dos profissionais.

Utilizou-se, para a coleta de dados do currículo lattes, um protocolo elaborado no LibreOffice com os seguintes campos: Autor, Título, Palavras-Chave, Fonte de Publicação, Tipologia Documental, Idioma e Ano.

\subsubsection{Bibliometria e Neobibliometria}

A Bibliometria surgiu no contexto da criação e expansão dos bancos de dados, em meio ao processo de redemocratização do país, como destacam Mostafa e Máximo (2003), Sacardo e Hayashi (2010). Para Vanti (2002, p. 155)

O uso de técnicas bibliométricas contribuiu de forma decisiva em épocas de recursos escassos, quando um bibliotecário deve resolver que títulos ou publicações periódicas podem ou não ser suprimidas de uma biblioteca. Indicadores de uso são obtidos, assim, para definir uma lista de publicações periódicas prioritárias e para prever a demanda futura, também são utilizados para avaliar a produtividade e a qualidade da pesquisa dos cientistas, por meio da medição com base nos números de publicações e citações dos diversos pesquisadores.

Como mencionado na seção 2.1, a bibliometria, que consiste na utilização de técnicas matemáticas e estatísticas para realizar a medição de índices da produção e da disseminação da produção científica, fazendo uso de métodos quantitativos, foi utilizada pela primeira vez em 1922, por Hulme (GUEDES, BORSCHIVER, 2005; VANZ, STUMPF, 2010).

Também compreendida como um conjunto de leis contribuintes dos fundamentos teóricos da Ciência da Informação. As principais leis que circundam a Bibliometria são: Lei de Bradford, que se refere a produtividade dos periódicos; Lei de Lotka, que correlaciona a produtividade científica de autores e as Leis de Zipf, que são associadas às frequências de palavras. 
De acordo com Quintanã Pena (2006), pode-se compreender a bibliometria como sendo "ante todo una estrategia metodológica inicialmente centrada en el análisis estructural y prognosis de la información contenida, principalmente, enpublicaciones científicas de investigación".

Isto posto, a bibliometria como forma de medição para medir o fluxo da informação, representa, algumas subdisciplinas como a cienciometria, a informetria e a webometria, apesar de apresentarem algumas semelhanças ou pontos de convergência, possuem características, enfoques e funções diferentes, porém todas inseridas no contexto bibliométrico (VANTI, 2002).

Nesse sentido, a aceitação da bibliometria como método quantitativo e qualitativo, bem como a visão das referências bibliográficas como rede de saber-poder, contribuiu para que os pesquisadores associassem a bibliometria a outras abordagens para a análise da produção científica. Isto posto, a utilização de outros métodos associados à bibliometria fez surgir o termo neobibliometria.

A neobibliometria, termo recente, pode ser compreendida como um neologismo da Bibliometria. O termo foi utilizado pioneiramente pelo pesquisador peruano Alberto Quintana Peña (1996, 2006 apud SILVA, 2012), em que o autor congrega outros métodos para a análise dos dados e não apenas os apresenta em estado bruto (SILVA, 2012).

A neobibliometria possibilita contribuições no delineamento teórico e metodológico de um campo, pois perpassa o viés quantitativo da bibliometria, como apontam as autoras Silva e Hayashi (2011), visto que verifica-se uma acrescente de estudos contemporâneos que apontam a ampliação de investigações que utilizam a bibliometria aliada às abordagens qualitativo-descritivas, gerando, com isso, a proposta de um novo termo para a área, a "neobibliometria" (SILVA, HAYASHI, HAYASHI, 2011; SILVA, MOSTAFA, 2013).

Lima, Hayashi, e Martinez (2014) reforça dizendo que esta abordagem tem produzido um conjunto significativo de pesquisas conhecidas como "estados da arte", reconhecidas pelo caráter descritivo de sua metodologia, que recorre à análise de categorias para discutir determinada produção acadêmica em diferentes áreas de conhecimento.

Deste modo, observa-se uma demanda crescente nos estudos bibliométricos; observase também que a bibliometria se alia cada vez mais a aportes sociocognitivos e se apresenta de maneira mais contextualizada, de modo que a rede de associações implica não somente aspectos quantitativos e numéricos, mas também aspectos muitas vezes políticos, culturais, sociais e filosóficos na constituição do saber. Essa rede hoje é percebida de maneira mais rica do que era percebida nas décadas de setenta ou oitenta, de acordo com Silva (2012).

Assim, verifica-se que a maioria das produções científicas, em sua metodologia, acaba aliando práticas quantitativas e qualitativas, e é nesse sentido que a neobibliometria atua, congregando institucionalmente práticas quali-quantitativas (SILVA, MOSTAFA, 2013).

Desse modo, pode-se suscitar a reflexão de que a neobibliometria passa a ser uma

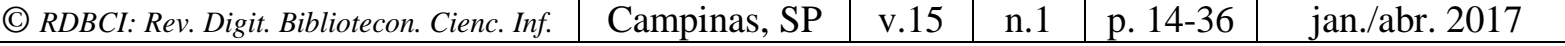


forma expandida da bibliometria, pois o contexto sócio-cognitivo ganha evidência.

\section{RESULTADOS}

Visto que a coleta de dados foi feita em duas frentes, apresentam-se os indicadores levantados com os resultados obtidos, assim como as discussões alinhadas ao referencial bibliográfico e os métodos e técnicas de pesquisa.

\subsection{Aplicação do Questionário}

Com relação ao questionário, foram recebidas 31 respostas, ou seja, 53\% dos profissionais responderam à pesquisa. Isto posto, apresentam-se as análises realizadas com relação à amostra.

$\mathrm{Na}$ primeira questão, que se refere ao gênero, verificou-se, assim como na área da Biblioteconomia, a predominância de profissionais do gênero feminino, o que configura um reflexo desse campo de atuação. Ferreira e Veiga (2013) destacam que cerca de $80 \%$ dos cargos de bibliotecários nas instituições são ocupados por mulheres.

Na segunda questão, buscou-se identificar a faixa etária dos profissionais. A faixa predominante é a de 31 a 35 anos com 41,4\%, seguida das faixas de 36 a 40 com $31 \%$ e de 26 a 30 anos com 24,1\%; ou seja, em sua maioria, o IFSP conta com profissionais jovens que deverão permanecer na instituição por um período considerável.

Com relação ao tempo de atuação, terceira questão, 65,5\% atua na instituição de 2 a 5 anos, $20,7 \%$ de 6 a 10 anos e $13,8 \%$ atua há 1 ano.

A quarta questão refere-se à titulação. Nesse caso, 62,1\% possui especialização, $31 \%$ possui mestrado, $3,4 \%$ possui doutorado e $3,4 \%$ possui graduação. Percebe-se que os profissionais em sua maioria buscaram qualificação superior à exigida na contratação.

A quinta questão objetivou verificar se os profissionais estudam atualmente. Os dados revelam que $65,5 \%$ não estuda e $34,5 \%$ está estudando.

A sexta questão solicitou informações referentes aos cursos que os profissionais frequentam atualmente. Os dados revelam uma linha abrangente de inserção, com cursos como: especializações, licenciaturas, mestrados e doutorados em áreas correlatas, tais quais: Ciência da Informação, Geografia, Educação, Pedagogia, entre outras.

A maioria dos profissionais considera importante realizar pesquisas referentes às rotinas de trabalho para depois publicá-las, sendo 92,9\% favorável e apenas 7,1\% não favorável, índices que representam os percentuais da sétima questão. A décima primeira 
questão destaca que, das publicações realizadas, $66,7 \%$ objetivou a contribuição das práticas laborais e 33,3\% não visava a contribuições nesse sentido.

Questionados se possuem publicações técnico-científicas, um total de $37 \%$ não possui, 33,3\% possui entre 1 e 5 publicações, $18,5 \%$ entre 6 e 10 publicações, 7,4\% mais de 16 publicações e $3,7 \%$ entre 11 e 15 publicações, refere que revelou a oitava questão.

Na nona questão, sobre as fontes de publicação, $50 \%$ considera interessante publicar as produções em periódicos, $35 \%$ em eventos, $14,3 \%$ em livros e 10,7\% em blogs e sites especializados. Essa questão permitiu a seleção de mais de uma alternativa.

A décima primeira questão solicitou dos participantes a relação das palavras-chave que descrevem as temáticas abordadas nas produções publicadas. Desse modo, as palavras foram contabilizadas e elencadas em duas colunas no Quadro 1-Temáticas de Pesquisa dos Bibliotecários do IFSP, no qual estão destacadas em negrito as palavras-chave que apresentaram mais de uma recorrência:

Tabela 1. Temáticas de Pesquisa dos Bibliotecários do IFSP

\begin{tabular}{|c|c|c|c|}
\hline Palavras-chave & Recorrência & Palavras-chave & Recorrência \\
\hline Leitura & 3 & Biblioteca Mista & 1 \\
\hline Bibliotecas Escolares & 3 & Incentivo à Leitura & 1 \\
\hline Competência Informacional & 2 & Atividades Culturais & 1 \\
\hline Bibliotecas & 2 & Saúde Baseada em Evidências & 1 \\
\hline $\begin{array}{l}\text { Marketing } \\
\text { Comportamento } \\
\text { Informacional }\end{array}$ & 1 & Estratégia de Busca & 1 \\
\hline Comportamento de Busca & 1 & Bases de Dados & 1 \\
\hline Pesquisa Científica & 1 & Indexação & 1 \\
\hline Divulgação Científica & 1 & Literatura & 1 \\
\hline Bibliometria & 1 & $\begin{array}{l}\text { Prospecção e Monitoramento } \\
\text { Informacional }\end{array}$ & 1 \\
\hline Marketing & 1 & Fontes de Informação & 1 \\
\hline Gestão do Conhecimento & 1 & Catalogação Descritiva & 1 \\
\hline Gestão da Informação & 1 & Recuperação da Informação & 1 \\
\hline Tipologias de Bibliotecas & 1 & Representação Temática & 1 \\
\hline
\end{tabular}




\begin{tabular}{|l|l|l|l|}
\hline Quadrinhos & 1 & Inteligência Coletiva & 1 \\
\hline Análise Documentária & 1 & Web Colaborativa & 1 \\
\hline Análise de Assunto & 1 & Informação e Tecnologia & 1 \\
\hline Estudo de Usuários & 1 & Internet & 1 \\
\hline $\begin{array}{l}\text { Paradigmas da Ciência da } \\
\text { Informação }\end{array}$ & 1 & Tempos da Ciência da Informação & 1 \\
\hline Arquitetura da Informação & 1 & Filosofia da Informação & 1 \\
\hline Privacidade & 1 & Ciência, Tecnologia e Sociedade & 1 \\
\hline $\begin{array}{l}\text { Apropriação do } \\
\text { Conhecimento }\end{array}$ & 1 & Comunicação Pública da Ciência & 1 \\
\hline
\end{tabular}

Fonte: Elaborada pelas autoras.

Percebe-se que os profissionais pesquisam temáticas próximas que, a partir deste estudo, poderão resultar em investigações e publicações conjuntas. Segundo os indicadores da décima segunda questão, 78,9\% das publicações não é em coautoria com profissionais da instituição e apenas $21,1 \%$ é fruto de publicações em coautoria com colegas de trabalho.

$\mathrm{Na}$ décima terceira questão, com relação à participação em eventos relacionados à área de atuação, 77,8\% dos profissionais participa de ao menos um evento ao ano, 18,5\% não participa de eventos e 3,7\% participa de eventos com frequência.

Do percentual (supracitado) que participa de eventos, $60 \%$ possui incentivo do IFSP e $40 \%$ não possui, dados referentes à décima quarta questão.

Quando os profissionais foram questionados, na décima quinta questão, se se consideram pesquisadores, $53,6 \%$ respondeu positivamente e $46,4 \%$ respondeu negativamente.

Para 71,4\% dos entrevistados, é interessante a articulação da categoria com vistas à produção e publicação de materiais técnico-científicos, sendo $71,4 \%$ favorável à organização de eventos e $28,8 \%$ favorável à criação de periódico especializado, como aponta a décima sexta questão.

A décima sétima e última questão se caracterizou como um espaço livre para que os colaboradores pudessem manifestar suas críticas quanto à pesquisa. Apresentam-se alguns trechos dos relatos:

“Ótima pesquisa, pois traçará um perfil dos bibliotecários pesquisadores do IFSP, assim como suas produções $e$ interesses com vistas ao aprimoramento pessoal $e$ profissional".

"Sugiro a criação de um periódico na base SEER, formado por parecerias conceituados na área".

"Gostaria de entender o objetivo da presente pesquisa. Desde já, estão de parabéns; é ótimo saber que nossa classe está unida, elevando os serviços e produtos da biblioteca".

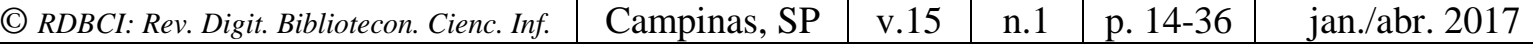




\section{"Ótima pesquisa, iniciativa bacana!"}

"Devido ao fluxo de trabalho e frequente falta de incentivo elou ajuda por parte da Instituição, sentimo-nos desmotivados a realizar produções, seja de qualquer espécie. Torço para que consigamos, ao longo dos anos, nos articular para produzir conteúdos relevantes ao nosso crescimento e dos demais colegas de profissão".

Os resultados dos questionários, aliados à análise feita no campo da Produção Bibliográfica dos Currículos Lattes, forneceram subsídios para alguns indicadores que serão apresentados na subseção 4.3 deste estudo.

\subsection{Plataforma e Currículo Lattes: Produções Bibliográficas}

Sabe-se que no universo acadêmico a plataforma lattes oferece uma série de recursos e possibilidades de levantamentos qualitativos acerca da trajetória dos pesquisadores, especificamente de suas produções bibliográficas. O campo de Produções Bibliográficas dos currículos lattes foram verificados por meio dos nomes dos profissionais listados em documento cedido pela Coordenadoria de Bibliotecas (CBI) da Reitoria do IFSP.

Foi estruturado um protocolo no aplicativo Microsoft Word para listar os seguintes pontos no ato da verificação:

1. Primeiramente, se os profissionais tinham ou não currículo lattes;

2. Quantitativo de produções bibliográficas;

3. Tipos de publicações.

De acordo com as verificações feitas, foi elaborado o Quadro 2 - Pesquisa Bibliográfica na Plataforma Lattes:

Quadro 2. Pesquisa Bibliográfica na Plataforma Lattes.

\begin{tabular}{|l|c|c|c|}
\hline & $\begin{array}{c}\text { Total de } \\
\text { publicações }\end{array}$ & $\begin{array}{c}\text { Média por } \\
\text { bibliotecário }\end{array}$ & Percentual \\
\hline Total de Bibliotecários no IFSP & $\mathbf{5 9}$ & & \\
\hline Total de Currículos Lattes Localizados & 44 & $74,6 \%$ \\
\hline Artigos Publicados (média entre todos) & 27 & 0,45 & \\
\hline $\begin{array}{l}\text { Artigos Publicados (média entre os que possuem } \\
\text { currículo lattes) }\end{array}$ & 27 & 0,61 & \\
\hline Resumos em Anais (média entre todos) & 44 & 0,74 & \\
\hline $\begin{array}{l}\text { Resumos em Anais (média entre os que possuem } \\
\text { currículoLlattes) }\end{array}$ & 44 & 1,00 & \\
\hline $\begin{array}{l}\text { Livros ou Parte (média entre os que } \\
\text { possuecurrículo lattes) }\end{array}$ & 13 & 0,29 & \\
\hline
\end{tabular}

Fonte: Elaborado pelas autoras.

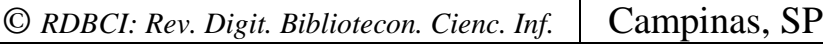

V.15

n.1 1 p. $14-36$

jan./abr. 2017 
Como forma diferente de demonstração, foi elaborado o gráfico exposto na Figura 2, que se refere à tipologia das publicações dos bibliotecários do IFSP.

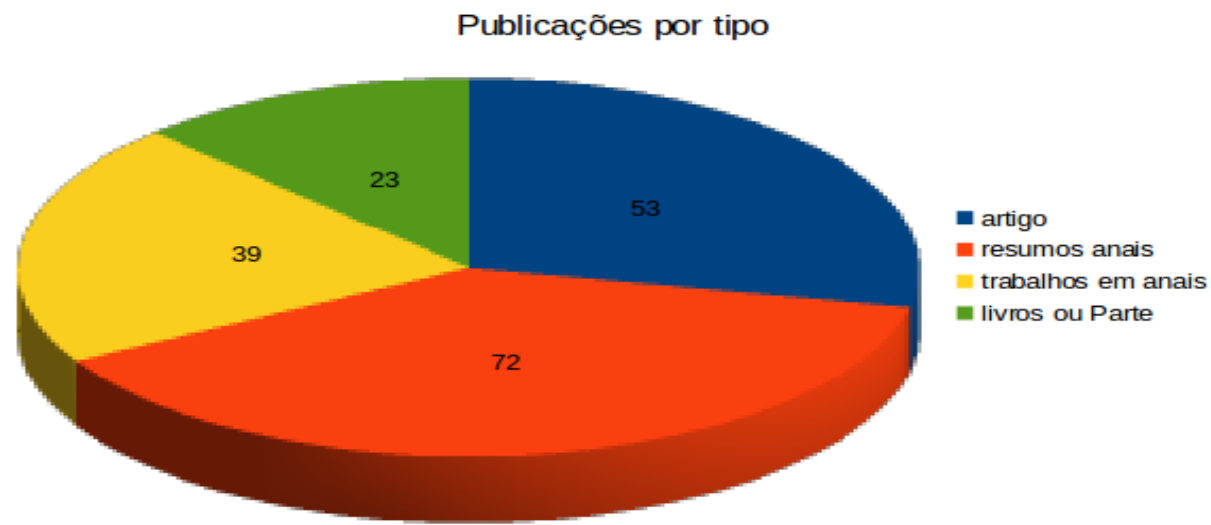

Figura 2. Tipologia das Publicações dos Bibliotecários do IFSP. Fonte: Elaborado pelas autoras.

Através do levantamento das produções bibliográficas pode-se verificar, de acordo com o Quadro 2, que 74,6\% dos entrevistados possui currículo na plataforma lattes, percentual relevante, embora seja salutar o estímulo aos demais profissionais a que realizem o cadastro na plataforma.

Com relação ao quantitativo identificado nas produções listadas, foi possível extrair alguns dados: os resumos em anais de eventos ocupam a primeira posição da produção bibliográfica desses profissionais, representando $72 \%$ de toda a produção bibliográfica levantada na plataforma. Os artigos ocupam o segundo lugar, representando 53\%. Em seguida, há os trabalhos em anais com 39\%, na terceira posição, e livros ou parte de livros na quarta posição com $23 \%$. O período em que foram verificadas as produções foi o intervalo de 2008 a 2015.

\subsection{Principais Análises}

Com base no referencial teórico, na metodologia adotada e nos instrumentos de coleta de dados utilizados, foi possível identificar:

- com relação ao referencial teórico:

- existe um vasto material relacionado as temáticas do estudo (produção científica, bibliometria, profissional bibliotecário), exceto sobre a temática da neobibliometria, neste sentido, sugere-se a amplitude de investigações e discussões sobre a neobibliometria e suas abordagens;

- a formação do profissional bibliotecário também como pesquisador merece ser mais explorada, como apontam Araújo (1996) e Demo (1998), visto que a educação e a pesquisa devem ser enxergadas como processos indissociáveis na formação de uma sociedade participativa; 
- vivencia-se a Sociedade do Conhecimento, de maneira que informação e conhecimento, atributos intangíveis com valor agregado ganham relevância tanto na economia, quanto na educação (FOUCAUT, 1988; DAVENPORT, PRUSAK, 1999; DZIEKANIAK, ROVER, 2011);

- na contemporaneidade a produção científica é um produto de relevância para o cenário das organizações de ensino, pois torna-se instrumento de avaliação de desempenho e visibilidade institucional, de modo que, independente de formação, os profissionais que produzem, possuem possibilidades de melhorar suas práticas teórico-laborais, assim como ofertar visibilidade para as instituições em que atuam (FERREIRA, 2011; SILVA, 2013).

- com relação aos bibliotecários-documentalistas do IFSP é possível delinear que:

- Profissionais em sua maioria do gênero feminino;

- Profissionais em sua maioria jovens;

- Profissionais em sua maioria com média de 5 anos de atividade no IFSP;

- A maioria possui qualificação além da exigida para o desempenho das funções;

- Produzem e publicam materiais técnico-científicos, especificamente Resumos em anais de eventos;

- Possuem interesse na organização de eventos institucionais, dentre outras informações;

- $74,6 \%$ possui currículo lattes, sendo interessante estimular os demais $(25,4 \%)$ a que realizem o cadastro na plataforma.

Isto Posto, vale ressaltar a viabilidade de demais investigações para corroborar com este primeiro estudo, de forma que seja possível ampliar as reflexões e detalhamentos.

Há que se estimular as produções e publicações em coautoria entre os profissionais, fomentar o aumento de suas participações em eventos da área, estimular a criação e organização de eventos institucionais.

Dessa maneira, deve-se ressaltar que iniciativas vêm sendo feitas tanto pela CBI quanto pela demanda dos próprios profissionais. Em abril de 2014, foi realizado o I Encontro de Bibliotecários do IFSP, evento que terá sua segunda edição no segundo semestre de 2016, conforme informações da CBI do IFSP.

Em suma, foi possível mapear e analisar, ainda que sumariamente, a produção técnico-científica dos bibliotecários-documentalistas do IFSP. Os resultados apontaram que os bibliotecários-documentalistas do IFSP produzem materiais técnicos, tais como: relatos de experiências, produtos de eventos-científicos e materiais científicos, tais como: artigos, dissertações e teses.

Estas produções contribuem para o desenvolvimento e aperfeiçoamento da categoria, 
favorece a busca de soluções para os problemas enfrentados em seus ambientes de trabalho, assim como auxiliar na evolução da área da Biblioteconomia e Ciência da Informação.

\section{CONSIDERAÇÕES FINAIS}

A metodologia adotada se mostrou satisfatória para o estudo. Destaca-se que a neobibliometria possibilita maior amplitude à interpretação e análise sociocognitiva, como aponta Silva. É válido ratificar que há a necessidade de ampliação do repertório investigativo acerca da neobibliometria e suas abordagens, pois esta amplia a rede de investigações epistemológicas (SILVA, 2012).

Destaca-se o pioneirismo da investigação, visto que, através deste estudo, foi possível, ainda que sumariamente, traçar um perfil dos bibliotecários-documentalistas do IFSP, que se manifestam como profissionais em sua maioria do gênero feminino, jovens, com formação superior à exigida para desempenho das funções e que se demonstram abertos às produções e publicações técnico-científicas. Cabe à instituição estimular o avanço desses profissionais, auxiliando-os na participação de eventos técnico-científicos e corporativos.

Propõe-se que os profissionais dialoguem mais entre si sobre possibilidades de investigações e publicações em grupos temáticos, visto que alguns profissionais possuem interesses e pesquisam temas afins.

As considerações apontam que os bibliotecários-documentalistas do IFSP produzem publicações técnico-científicas; no entanto, poderão produzir mais, visto que tal feito contribui para o desenvolvimento e aperfeiçoamento da categoria, aproxima relações institucionais entre os câmpus e favorece a busca de soluções para os problemas enfrentados em suas práticas laborais, além de evidenciar seus respectivos câmpus e bibliotecas nos cenários técnico-científico nacional e internacional.

Verificou-se ainda que ações isoladas são realizadas; porém, se essas ações passarem para o nível colaborativo, apresentarão um potencial maior e mais amplo. 


\section{PRODUCCIÓN TÉCNICO-CIENTÍFICA DE LOS BIBLIOTECARIOS DEL INSTITUTO FEDERAL DE SÃO PAULO: UN ESTUDIO NEO-BIBLIOMÉTRICO}

RESUMEN: Las bibliotecas y los bibliotecarios-documentalistas del Instituto Federal de Educación, Ciencia y Tecnología de São Paulo (IFSP) han sido estudiados en investigaciones científicas, pero aún no ha sido identificado ninguna investigación que levantase y mapease la producción científica de estos profesionales. Este estudio tuvo como objetivo mapear y analizar la producción técnico-científica de los bibliotecarios-documentalistas de la institución referida. El enfoque metodológico consistió en la realización de investigación teórica y empírica, en la cual fue priorizado el abordaje neo-bibliométrico. Por consiguiente, las herramientas de la Bibliometría se asociaron a la aplicación del cuestionario a los profesionales de la institución. Los resultados indicaron que la mayoría de los profesionales del IFSP: es del género femenino; tiene una calificación más alta que la requerida para el ejercicio de sus funciones; tiene alguna publicación técnico-científica; considera importante el desarrollo de publicaciones técnico-científicas, así como la creación de medios de comunicación y eventos. Sin embargo, las autoras sugieren algunas formas de fortalecer la visibilidad de la categoría: incentivo para aumentar las publicaciones técnico-científicas; incentivo a la creación y actualización del currículum lattes; incentivo a la producción de publicaciones con otros pesquisidores, pues algunos profesionales investigan temas similares; estímulo a la participación en eventos y publicaciones técnico-científicas. La conclusión de este estudio indica que los bibliotecarios-documentalistas del IFSP producen publicaciones técnico-científicas, pero pueden producir más, ya que este hecho contribuye al desarrollo y mejora de la categoría, estrecha los vínculos institucionales entre los campus, favorece la búsqueda de soluciones a los problemas que los profesionales enfrentan, además de destacar sus campus y sus bibliotecas en el escenario técnico-científico nacional e internacional.

PALABRAS ClAVE: Producción Técnico-Científica. Bibliotecarios-Documentalistas. Instituto Federal de São Paulo. Neo-Bibliometría.

Submetido em: 11/06/2016

Aceito em: 17/11/2016

Publicado em: 24/11/2016 


\section{REFERÊNCIAS}

ARAUJO, Eliany Alvarenga de. A importância da pesquisa para a formação e o desenvolvimento acadêmico. Informação \& Informação, v. 1, n. 1, p. 18-21, jan./jun. 1996.

BAGNO, Marcos. Pesquisa na escola: o que é, como se faz. 21. ed. São Paulo: Ed. Loyola, 1998.

BELL, Daniel. O advento da sociedade industrial: uma tentativa de previsão social. São Paulo: Cultrix, 1978.

BORDONS, Maria.; ZULUETA-GARCIA, Maria Angeles. Comparison of research team activity in two biomedical fields. Scientometrics. vol. 40, n.3, 1997. Disponível em: <http://link.springer.com/article/10.1007\%2FBF02459290>. Acesso em: 10 jan. 2016.

BRASIL. Lei no 4.084 de 30 de junho de 1962. Dispõe sobre a profissão de bibliotecário e regulamenta o exercício. 1962. Disponível em:

<https://legislacao.planalto.gov.br/legisla/legislacao.nsf/viwTodos/F476FA87581D508F0325

69FA00721F5B?OpenDocument\&HIGHLIGHT=1, bibliotec\%E1rio>. Acesso em: 12 jan.

2016.

DANUELLO, Jane Coelho; GUIMARAES, José Augusto Chaves Guimarães. Produção científica docente em tratamento temático da informação nos cursos de Biblioteconomia do Mercosul: uma análise preliminar. Transinformação [online]. vol.17, n.2, 2005. Disponível em: < http://dx.doi.org/10.1590/S0103-37862005000200004>. Acesso em: 09 jan. 2016.

DEMO, Pedro. Educar pela pesquisa. 3.ed. Campinas: Autores Associados, 1998.

DZIEKAMAK, Gisele; ROVER, Aires. Sociedade do conhecimento: características, demandas e requisitos. DataGramaZero - Revista de Informação. vol.12, n.5, out/2011. Disponível em: 〈http://www.dgz.org.br/out11/Art_01.htm>. Acesso em: 11 jan. 2016.

FERREIRA, Maria Mary. Produção científica na Biblioteconomia: as pesquisas realizadas no programa de educação tutorial(PET) e seus reflexos na formação acadêmica. Revista EDICIC, v.1, n.4, p.99-108, Oct./Dic. 2011. Disponível em: <http://www.edicic.org/revista/>. Acesso em 23 fev. 2016.

FERREIRA, Maria Mary; VEIGA, Marcos Aurélio Pereira. Bibliotecários, trabalho e salário: o profissional da informação na sociedade do mercado. In: Jornanda Internacional de Políticas Públicas, 6, 2013. São Luíz, MA. Anais... São Luís, MA, 2013. Disponível em: <http://www.joinpp.ufma.br/jornadas/joinpp2013/JornadaEixo2013/anais-eixo2transformacoesnomundodotrabalho/bibliotecarios-trabalhoesalariooprofissionaldainformacaonasociedadedemercado.pdf>. Acesso em: 06 abr. 2016.

FOUCAULT, Michel. Microfísica do poder. Rio de Janeiro: Graal, 1988.

GIL, Antônio Carlos Gil. Como elaborar projetos de pesquisa. 4. ed. São Paulo: Atlas, 2008.

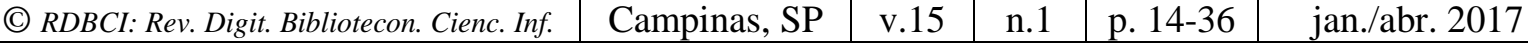


GUEDES, Vânia Lisboa da Silveira.; BORSSCHIVER, Suzana. Bibliometria: uma ferramenta estatística para a gestão da informação e do conhecimento, em sistemas de informação, de comunicação e de avaliação científica e tecnológica". In: Encontro Nacional de Ciência da Informação, 6, Salvador: Anais... Disponível em: 〈http://goo.gl/CghVp7>. Acesso em: 18 nov. 2016.

INSTITUTO FEDERAL DE SÃO PAULO. 2015. Disponível em: <http://www.ifsp.edu.br/index.php/instituicao/ifsp.html >. Acesso em 03 nov. 2015.

LIMA, Debora Correa de; HAYASHI, Maria Cristina Piumbato Innocentini; MARTINEZ, Claudia Maria Simões. Estudo neobibliométrico sobre procedimentos para ensino de vocabulário. Distúrb Comun, vol.26, n.3, São Paulo, set. 2014. Disponível em: $<$ http://revistas.pucsp.br/index.php/dic/article/viewFile/16884/15213>. Acesso em: 21 nov. 2016

MOSTAFA, Solange Puntel; MÁXIMO, Luis Fenando. A produção científica da ANPED e da Intercom no GT da educação e comunicação. Ci. Inf., Brasìlia, v. 32, n. 1, p. 96-101, jan./abr. 2003. Disponível em: 〈http://www.scielo.br/pdf/ci/v32n1/15977.pdf>. Acesso em 31 out. 2015.

NEHMY, Rosa Maria Quadros; PAIM, Isis. Repensando a sociedade da informação.

Perspectivas em Ciência da Informação, v. 7, n. 1, p. 9-21, jan./jun. 2002. Disponível em: $<$ http://portaldeperiodicos.eci.ufmg.br/index.php/pci/article/view/410/223>. Acesso em: 20 de nov. 2015.

QUINTAÑA PENA, Alberto. Análisis neo-bibliométrico de las Investigaciones de tesis en la Escuela Académico-Profesional de Psicología UNMSM. Revista de Investigación en Psicología, v. 9, n. 1, p. 81-99, 2006. Disponível em:

<http://sisbib.unmsm.edu.pe/Bvrevistas/Investigacion_Psicologia/v09_n1/pdf/a06v9n1.pdf>. Acesso em 31 out. 2015.

RAMPAZZO, Lino. Metodologia científica para alunos dos cursos de graduação e pósgraduação. 3. ed. São Paulo: Loyola, 2005. 145 p.

REZENDE, Yara. Informação para negócios: os novos agentes do conhecimento e a gestão do capital intelectual. Ciência da Informação, Brasília, v. 31, n. 2, p. 120-128, maio/ago. 2002. Disponível em: 〈http://www.scielo.br/pdf/ci/v31n2/12915.pdf $>$. Acesso em: 10 jan. 2016.

SACARDO, Michele Silva; HAYASHI, Maria Cristina Piumbato Innocentini. A pesquisa em educação física na interface com a educação na região centro-oeste do Brasil: uma análise epistemológica e bibliometrica. In: COLÓQUI DE EPISTEMOLOGIA DA EDUCAÇÃO FÍSICA, 5., Maceió, Anais... 2010. Disponível em: <http://congressos.cbce.org.br/index.php/cepistef/v_cepistef/paper/view/2634>. Acesso em: 18 nov. 2016.

SANTOS, Cintia Almeida da Silva. As unidades de informação dos Institutos Federais no apoio ao desenvolvimento da ciência e da tecnologia: um estudo de percepção sociocognitiva com o uso do protocolo verbal em grupo. 248f. Dissertação (Mestrado em Ciência, Tecnologia e Sociedade) - Centro de Educação e Ciências Humanas, Universidade

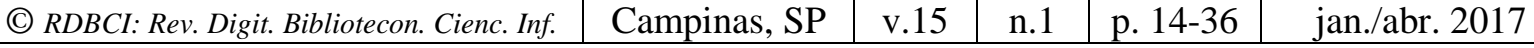


Federal de São Carlos, 2012.

SCHWARTMAN, Simon.; CASTRO, Cláudio de Moura (Ed.). Há produção científica no Brasil? Pesquisa universitária em questão. Campinas, SP: Editora da UNICAMP, 1986. Disponível em: < https://archive.org/details/HaProducaoCientifica>. Acesso em: 02 nov. 2015.

SILVA, Márcia Regina da; HAYASHI, Carlos Roberto; HAYASHI, Maria Cristina Piumbato Innocentini. Análise bibliométrica e cientométrica: desafios para especialistas que atuam no campo. InCID: R. Ci. Inf. e Doc., Ribeirão Preto, v. 2, n. 1, p. 110-129, jan./jun. 2011. Disponível em:

<http://www.revistas.usp.br/incid/article/view/42337/46008>. Acesso em: 19 nov. 2016.

SILVA, Márcia Regina da; HAYASHI, Maria Cristina Piumbato Innocentini.

Neobibliometria no contex to do neodocumentalismo. In: CRIPPA, Giulia; MOSTAFA, Solange Puntel (Orgs). Ciência da informação e documentação. Campinas: Alínea; 2011. p.71-84.

SILVA, Márcia Regina da; MOSTAFA, Solange Puntel. A documentalidade das citações bibliográficas. Dossiê Epistemologias e Teorias da Educação. Filosofia e Educação, Campinas, v. 5, n. 2, p. 103-119, out. 2013. Disponível em:

<http://ojs.fe.unicamp.br/ged/rfe/article/viewFile/5318/4503>. Acesso em: 18 nov. 2016.

SILVA, Márcia Regina da. Agenciamento das citações bibliográficas. 6 Campinas.

Seminário de Epistemologias e Teorias em Educação. EPISTED - 2012. Disponível em: <https://www.fe.unicamp.br/eventos/ged/episted/EPISTED/paper/viewFile/101/56>. Acesso em 3i out. 2015.

SILVA, Márcia Regina da; SILVA, Jeane dos Santos; SANTOS-ROCHA, Ednéia Silva.O profissional da informação como produtor de conhecimentos: análise bibliométrica da produção científica de bibliotecários. Liinc em Revista, Rio de Janeiro, v. 9, n. 1, p. 103-123, maio 2013. Disponível em: 〈http://revista.ibict.br/liinc/index.php/liinc/article/view/530/403>. Acesso em: 12 jan. 2016.

SIMEC. Instituto Federal de Educação, Ciência e Tecnologia de São Paulo - mapa dos câmpus 2016. Elaboração cartográfica: Leandro Henrique da Silva. Arte final: Vitor Hugo de Rosa. 2016. Disponível em: < http://www.ifsp.edu.br/index.php/mapa-dos-campi.html>. Acesso em: 18 nov. 2016.

SMIT, Johanna Willelmina; DIAS, Eduardo Wense; SOUZA, Rosali Fernandes de. Contribuição da pós-graduação para a Ciência da Informação no Brasil: uma visão.

DataGramaZero - Revista de Ciência da Informação, v.3, n.6, dez. 2002. Disponível em: <http://ridi.ibict.br/handle/123456789/110>. Acesso em: 12 jan. 2016.

SOUZA, Edivanio Duarte de; OLIVEIRA, Dalgiza. A análise documentária no grupo Temma: dos indícios às evidências da formação de unidades discursivas. Ci. Inf. [online], vol.36, n.2, pp.74-84, maio 2007. Disponível em: < http://dx.doi.org/10.1590/S0100$19652007000200008>$. Acesso em: 02 jan. 2016.

VANTI, Nadia Aurora Peres. Da bibliometria à webometria: uma exploração conceitual dos

\begin{tabular}{|c|c|c|c|c|c|}
\hline (C) RDBCI: Rev. Digit. Bibliotecon. Cienc. Inf. & Campinas, SP & v.15 & n. 1 & p. $14-36$ & jan./abr. 2017 \\
\hline
\end{tabular}


mecanismos utilizados para medir o registro da informação e a difusão do conhecimento. Ci. Inf., Brasília, v. 31, n. 2, p. 152-162, maio/ago. 2002. Disponível em:

<https://outlook.live.com/owa/?path=/attachmentlightbox>. Acesso em: 21 nov. 2016.

VANZ, Samile Andréa de Souza; STUMPF, Ida Regina Chittó. Procedimentos e ferramentas aplicados aos estudos bibliométricos. Informação e Sociedade: estudos, João Pessoa, v. 20, n. 2, pp. 67-75, maio-ago . Disponível em:

<http://www.ies.ufpb.br/ojs/index.php/ies/article/view/4817/4358>. Acesso em: 18 nov. 2016.

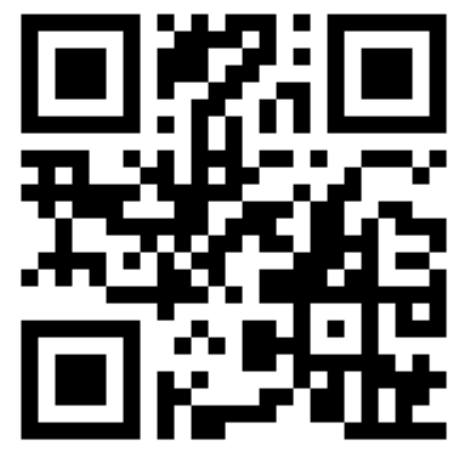

